and the gown, is, under the present conditions of college students, fast passing away. This advantage of the presence of a body of student has two applications: The students may be local, or of a type that comes from abroad. If the students are local, the college gives the best advantage possible for the education of sons and daughters at home. If the students be from outside the community, the presence of these students gives a larger type of thought and of feeling and of vision to all.

4. To offer to the community an example of a historic life. The university, or the college, is the most lasting of all the creations of men. American institutions are new like America herself, but they are, like Harvard, among the oldest of all the intellectual and spiritual works of the new world. Rich is the meaning which such continuity of life may have for a community. This community may have a special relationship in opening opportunities for the abler class of the community to link their life and character with these creations through the establishment of professorships, of buildings, or the laying down of endowments.

It also may be noted that the college gives to the community noble types of architecture and the establishment of libraries, galleries of art and museums of many sorts. In a superficial way the material relationship is significant and impressive.

\title{
THE FUNCTION OF COMMERCIAL AMUSEMENTS
}

\section{Norman E. Richardson, Ph.D.*}

In view of present-day conditions in practically all of the communities on the American continent, commercial amusements may be looked upon as a necessary and inevitable development. They are the product of forces which are not superficial or transitory, but which inhere in the very nature of our social fabric. Some of the conditions which have made them both necessary and commercially profitable are as follows:

I. The shortening of the hours of labor-a world-wide movement in the interest of the shorter day is gaining momentum with great rapidity. Every industry has faced the demand of labor for shorter hours of work and almost universally has yielded to these demands. But, to shorten the hours of labor does not reduce the number of hours in the day. It does mean that laborers have more time on their hands. The resulting wide-spread idleness is one of

*Professor Richardson is head of the Department of Religious Education in Boston University. 
the factors making some form of amusement or recreation inevitable.

2. The present age is characterized by innumerable mechanical devices, introduced for the purpose of saving labor. More and more, the manufacturers are using machines rather than men. As this process of perfecting mechanical devices goes on the tasks remaining to the laborer become fewer in number and more highly specialized. This means that human labor is becoming mechanical. The strain rests upon smaller and smaller areas of brain, nervous system and muscles. Both in the character and in the rate of muscular movements the laborer is asked to adjust himself to the requirements of machinery. The result is that in the interest of physical and mental integrity, some form of activity that will supplement the ordinary work must be discovered. The more widespread the introduction of machinery, the more wide-spread the demand for play which will protect the mind and the body from deformity.

3. The very intensity of our modern life demands that opportunities for relaxation be provided. The strain of toil is greater than ever before. Lines of communication are multiplying rapidly. Points of contact are now innumerable; congestion frequently occurs. The result is that life is apt to lose its spontaneity and ordinary vigor; nervous breakdowns occur. Persons afflicted with neuresthenia are met on every hand. Commercialized amusements help their patrons to shake off the interests that tend to fasten themselves like barnacles upon the mind. They make necessary relaxation possible and convenient.

4. In spite of this intensity of modern living, dull monotony creeps in at many points. The one who is doing highly specialized work and doing that only does not discover the rhythm or the climaxes found under normal conditions. To make one small part of a wagon year after year is not like making every part of the wagon and coming at intervals to that experience of seeing the perfect and complete product, then starting at the beginning again to build another wagon. The very monotony of high specialization demands opportunities of escape from the commonplace drudgery and routine fidelity. This, commercialized amusement affords.

5. There is born also in the midst of social relationships a demand for the theatre, the "movies," professionalized play and social rendezvous centers. High specialization in business and profession tends to lead toward social isolation or at best-social stratification. Social strata rapidly become hardened along professional, financial lines. Hence, there springs up a demand for the 
large, popular group of folks brought together through their play interests.

7. The restriction of the modern home as a place for play is also significant. In the congested centres of population the equipment necessary for natural relaxation and amusement is lacking. The family that is pigeon-holed in a modern apartment must break through this narrow confinement at some point. The instinctive demand for play, the larger opportunities for leisure-time activities and the inherent attractiveness of commercialized amusements all make these institutions increasingly popular. Commercialized amusements, therefore, are a necessary supplement to the modern home. They offer convenient opportunities for that which the home should but cannot provide.

8. When the project of supplying the community with amusement is thus made necessary, it becomes commercially profitable and leads to the development of a profession. People who have not the strength, the time, the opportunity, the equipment or the social relations which make play possible are willing to pay to be played upon, but they demand that their substitute be highly skilled. Ideals of amusement may become more elevated as the power of participation in play decreases. The epidemic of "spectatoritis" that has swept through our American communities is damagingmentally and physically. Indeed, it is often morally harmful. Nevertheless, professional amusement makers can be of great service to the community in toning up the community ideals with reference to the technique of play. Professional baseball has done much for amateur baseball. Mary Pickford has disengaged whole areas of dramatic ability that otherwise would have remained inert.

\footnotetext{
The Annual Meeting has been transferred to New York City, at Hotel McAlpine on March 5th and 6th.
} 